\title{
A Technique for the Evaluation of Instantaneous Heat Fluxes for the Horizontal Strip Casting of Aluminum Alloys
}

\author{
Pedro G. Q. NETTO, Roberto P. TAVARES, ${ }^{1)}$ Mihaiela ISAC ${ }^{2)}$ and Roderick I. L. GUTHRIE ${ }^{3)}$ \\ Formerly at McGill University. Now at Universidade Federal Fluminense, Volta Redonda, Brazil. \\ 1) Formerly at McGill University. Now at Universidade Federal de Minas Gerais, Brazil. \\ 2) Department of Physical Metallurgy, University of Bucharest, Romania, also McGill Metals Processing Centre, M.H. Wong \\ Building, McGill University, 3610 University Street, Montreal, Quebec, H3A 2B2, Canada. \\ 3) McGill Metals Processing Centre, M.H. Wong Building, McGill University, 3610 University Street, Montreal, Quebec, H3A \\ 2B2, Canada.
}

(Received on February 14, 2000; accepted in final form on June 21, 2001)

\begin{abstract}
Transient heat transfer between solidifying light metals strips and a moving substrate has been investigated. For this purpose, an experimental apparatus was constructed, consisting of a cold moving substrate onto which molten metal from a containment mold is deposited. The substrate was flame sprayed with various commercial coatings while its speed and the thicknesses of strip produced matched industrial values. The primary objective of this work was to study the effects of some important variables, such as roughness of substrate, type of coating, thickness of strip and initial superheat, on heat fluxes. Substrate speeds in the range of $0.4-1.2 \mathrm{~m} / \mathrm{s}$ were employed and strips with thicknesses between 1 and $5 \mathrm{~mm}$ were produced. The heat fluxes were determined "inversely" by an inverse heat transfer technique, using temperature measurements from thermocouples embedded within the substrate. Peak heat fluxes between 0.6 and 3.0 MW/m² were found for the diverse experimental conditions investigated. The heat transfer coefficients were deduced using a one-dimensional, finite-difference model, based on the corresponding calculated heat fluxes. Values of $h$ ranged from $700-5000 \mathrm{~W} / \mathrm{m}^{2} \cdot \mathrm{K}$. The various coatings used, and the different levels of substrate roughness, contributed to the wide range of $h$ values reported. The heat transfer coefficient was found to increase with initial superheat, thickness of strip and smoother coatings. Correlations were derived between peak heat fluxes and the most significant variables. More importantly, the transient evolution of $q$ and $h$ after their peak values were assessed and good correlations could be derived. The findings of this work are believed to be useful for industrial processes, since they give a better picture of the influence of some important variables on the heat transfer involved for this particular type of metal-substrate contact. This is relevant, for example, to horizontal direct strip casting processes currently under investigation for the production of low carbon steel strips.
\end{abstract}

KEY WORDS: horizontal strip casting; aluminum alloys; single-belt caster; inverse heat conduction.

\section{Introduction}

Strip casting processes produce thin strips directly from liquid metal, thereby eliminating rolling steps and associated annealing/reheating operations. Strip versus slab casting operations have the potential for very important reductions in operating and investment costs. The major research programs on this subject, world-wide, demonstrate steelmakers' commercial interests in the anticipated benefits of such technologies.

Recent attempts to develop near-net-shape casting have shown that one of the most important aspects to be considered is the interfacial heat transfer between the liquid melt and the moving substrate. For the wide range of technologies under development, different types of contact can occur between the solidifying metal and the solid substrate. The values of heat fluxes and heat transfer coefficients reported in the literature reflect this reality, differing in some cases by several orders of magnitude, as can be concluded from Wang and Matthys' recent literature review. ${ }^{1)}$
Therefore, if one is interested in having a realistic estimate of the heat transfer fluxes involved in a particular process, one must perform experimental measurements either on-site or, more commonly, on an experimental apparatus that should match, as closely as possible, the real process.

Among the various casting configurations that have been tested for near-net-shape casting, the roll processes and the belt processes are the most common. Processes have also been developed for very thin strips or ribbons, for free-jet spinning, for planar flow casting and for spray deposition. As mentioned before, thermal contact between the melt and the substrate can differ in these processes, depending on geometrical configuration, casting speed, strip thickness, hydrostatic pressure, etc.

Recently, Wang and Matthys ${ }^{1)}$ presented a comprehensive assessment of data currently available for the various near-net-shape casting processes. They concluded that a significant amount of data for twin-roll casters and melt spinning had already been generated; however, for other 
processes, such as belt casters, relatively little data are available and even these have been obtained under diverse experimental conditions.

Farouk et al. ${ }^{2)}$ performed measurements of heat fluxes between a belt and either liquid aluminum or steel. Their apparatus was motionless, nor was any relationship between heat fluxes and relevant variables proposed.

Chen and co-workers ${ }^{3)}$ investigated some of the parameters involved in the interfacial heat transfer behavior in free-jet casting of Wood's alloy onto a moving substrate. The thicknesses of ribbons varied between 0.1 and 0.25 $\mathrm{mm}$.

A simulation of low-carbon steel strip casting was carried out by Couture et $\left.a l .{ }^{4}\right)$ They used a copper mold moving at very low speed for the substrate. Their work focussed on microstructural characterization.

Strezov and Herbertson, ${ }^{5)}$ made a recent contribution to the subject, studying heat transfer characteristics between a copper substrate embedded in a flat wedge and a stainless steel bath into which the wedge was rapidly immersed. They investigated the following variables: substrate texture, gas atmosphere, immersion velocity and melt superheat.

The objective of the present study was to investigate interfacial heat transfer between solidifying aluminum and aluminum alloys strips and a cold moving substrate, focussing on the most important parameters that affect interfacial heat fluxes. To achieve this objective, an experimental apparatus consisting of a stationary refractory mold and a rapidly moving substrate simulating a DSC (Direct Strip Casting) caster operation, was built. The substrate was capable of moving at speeds within the range intended for industrial single-belt casters, ${ }^{6}$ ) and the thicknesses of the strips were chosen accordingly. The parameters studied in the present work were: substrate coatings, substrate roughness, superheat and substrate speed.

\section{Experimental Apparatus and Calculation Proce- dures}

\subsection{Description of the Experimental Apparatus}

A schematic view of the strip casting simulator (SCS) is given in Fig. 1. The apparatus is composed of a containment mold, a gas furnace, a flat steel bar onto which metal is to be deposited, together with a pneumatic piston to push the bar, at the desired speed of casting, and a data acquisi- tion system. In the middle of the bar, there is a $3 \mathrm{~mm}$ thick, $50 \mathrm{~mm}$ wide and $1 \mathrm{~m}$ long groove for metal deposition. The bar slides over lubricated cylindrical bars.

The $10 \mathrm{~mm}$ thick bars were coated by flame-spraying at the Hazelett Strip Casting Corporation. Four different types of coatings were applied on respective bars, each with two levels of roughness, as shown in Table 1. Holes were drilled along the longitudinal axis of the bar, at chosen depths, in order to embed thermocouples so as to be able to determine local heat fluxes to the substrate.

The bond coat of the coatings was Metco 480NS. The values of $R_{\mathrm{a}}$ (surface arithmetic average roughness) were derived from five readings of which the highest and lowest were eliminated and the remaining three averaged. Further information concerning coatings compositions and degrees of roughness are given in Ref. 7).

The speed of the substrate was calibrated using a voltimeter, a He-Ne laser source, a steel sheet with holes equally spaced along the sheet and a photo-transistor connected to a voltimeter imposing a constant voltage. Further details of this methodology can be found elsewhere. ${ }^{8)}$

Since the bar of the strip casting simulator is subject to inertia during its initial period of acceleration, it took time (a fraction of a second) for the flat bar to assume constant axial speed. Evidently, determining the position where the bar reaches its final velocity of translation is important in positioning the embedded thermocouples, as detailed below. Three different speeds were used in this work: 0.4 , 0.8 and $1.2 \mathrm{~m} / \mathrm{s}$.

Three pairs of thermocouples were positioned along the center of the substrate, at depths of $1.58 \mathrm{~mm}$ and 4.87 $\mathrm{mm}$ from the surface, at longitudinal distances of $0.39,0.51$

Table 1. Types of coatings and roughness.

\begin{tabular}{|c|c|c|c|c|}
\hline Type of Coating & $\begin{array}{l}\text { Coating } \\
\text { Number }\end{array}$ & $\begin{array}{c}\text { Chemical } \\
\text { Composition } \\
\text { (mass \%) }\end{array}$ & $\begin{array}{c}\text { Thickness } \\
(\mu \mathrm{m})\end{array}$ & $\begin{array}{c}\text { Roughness } \\
\left(\mathrm{R}_{\mathrm{a}}\right) \\
(\mu \mathrm{m}) \\
\end{array}$ \\
\hline MATRIX Z - ALUMINA & 1 & $100 \% \mathrm{Al}_{2} \mathrm{O}_{3}$ & 75 & 11 \\
\hline MATRIX HC - NICKEL based & 2 & $\mathrm{Ni}-17,5 \mathrm{Cr}-5,5 \mathrm{Al}-2,5 \mathrm{Co}-0,5 \mathrm{Y}_{2} \mathrm{O}_{3}$ & 75 & 13 \\
\hline MATRIX M - YTTRIA stabilized ZrO, & 3 & $92 \% \mathrm{ZrO}_{2}-8 \% \mathrm{Y}_{2} \mathrm{O}_{3}$ & 75 & 11 \\
\hline MATRIX Y- $\mathrm{MgO}-\mathrm{ZrO}_{2}$ & 4 & $76 \% \mathrm{ZrO}_{2}-24 \% \mathrm{MgO}$ & 75 & 11 \\
\hline MATRIX Z - ALUMINA & 5 & same as 1 & 75 & 18 \\
\hline MATRIX M - YTTRIA & 6 & same as 3 & 75 & 18 \\
\hline MATRIX HC - NICKEL & 7 & same as 2 & 75 & 17 \\
\hline MATRIX Y - $\mathrm{MgO}-\mathrm{ZrO}_{2}$ & 8 & same as 4 & 75 & 17 \\
\hline
\end{tabular}

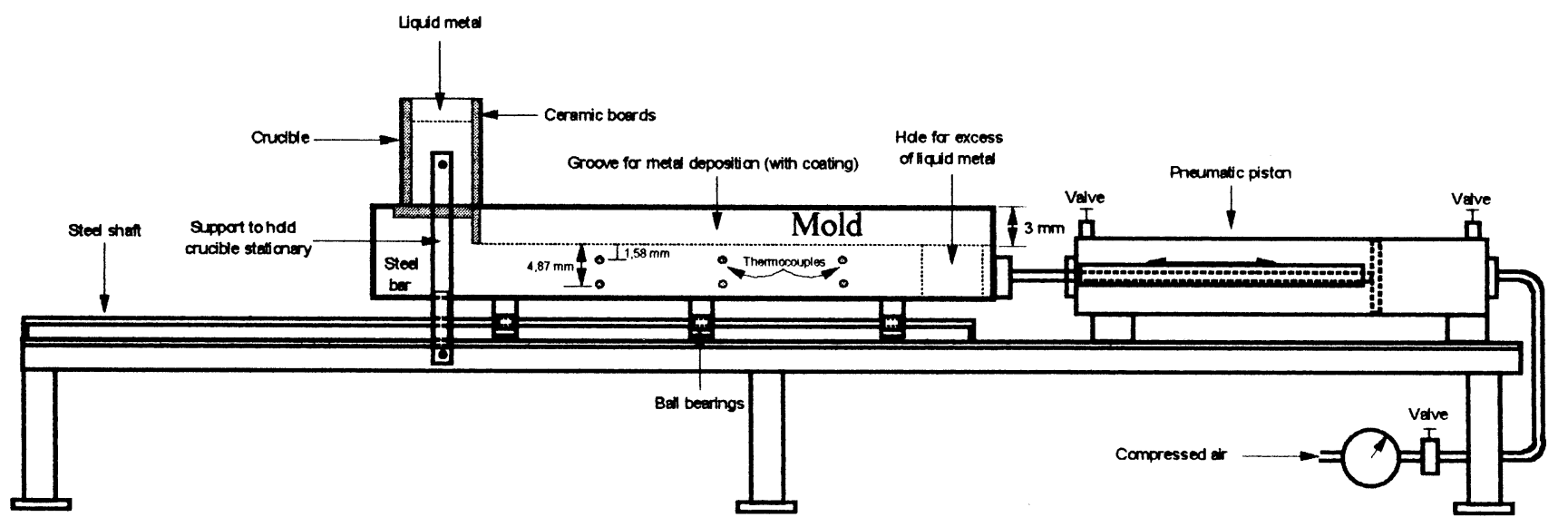

Fig. 1. Schematic of the strip casting simulator. 
and $0.63 \mathrm{~m}$ from the leading edge of the bar. The thermocouples were type $\mathrm{K}$ and were bonded to the substrate by OMEGATHERM $^{\circledR}$ ( High Thermal Conductivity Paste). Temperature data at these points were acquired at a rate of $10-30 \mathrm{~Hz}$, by an Omega data acquisition system (Omega International Co.), in the "Low Noise" option. It is an option in the data acquisition system where a lower frequency is used to get a more stabilized output. Care was taken to position the thermocouples in those regions of the bar where it was moving at the constant speed desired. The diameter of the wire was $0.25 \mathrm{~mm}$.

A gas furnace was used to melt the aluminum and aluminum alloys and a ladle spoon was used to pour the molten metal into the mold. Before pouring, argon was injected into the melt, for degassification. The static mold comprised a carbon steel box lined with refractory boards. Its main function was to hold the liquid metal without significant heat losses before the machine was started. The experiments were carried out ten seconds after the mold had been filled, so as to remove any effect of pouring turbulence within the melt on subsequent strip solidification.

The machine was started by electric power and, as soon as the piston started moving the bar, the metal flowed from the mold to the groove through an opening on the bottom of the mold, which was blocked at time zero. At that point, the data acquisition system had already been activated. At the end of the "cast", excess metal remaining within the mold flowed through a matching opening at the end of the bar, and was collected in a sump.

The initial height of the metal in the mold was kept constant, in the order of $6 \mathrm{~cm}$. Considering that there was an excess of metal in the mold, it was calculated by mass balance that the final height of metal was $2 \mathrm{~cm}$. Therefore, using a discharge coefficient of $0.8^{9)}$ and applying the wellknown formula:

$$
v=C_{\mathrm{D}} \sqrt{2 g h}
$$

the initial and final horizontal velocities of the liquid metal contacting the substrate bar were found to be 0.87 and $0.5 \mathrm{~m} / \mathrm{s}$, respectively. These values fall within the range of substrate speeds $(0.4-1.2 \mathrm{~m} / \mathrm{s})$, that were compatible with the belt speeds, in terms of reducing the likelihood of any hydraulic jumps.

A thermocouple was placed in the mold to determine the superheat of the metal. Different levels of superheat were investigated, ranging from 0 to $50^{\circ} \mathrm{C}$.

\subsection{Calculation of Heat Fluxes}

A one dimensional finite-difference model was developed to solve the inverse transient heat conduction equation in the vertical sense of the substrate:

$$
\frac{\partial}{\partial x}\left(k \frac{\partial T}{\partial x}\right)=\rho c \frac{\partial T}{\partial t}
$$

This approach was valid, given the high lateral speed of the bar, that rendered axial conduction effects less than $3 \%$ of vertical components, at velocities of $1 \mathrm{~m} / \mathrm{s}$. The heat fluxes were determined using a second order regularization method $^{10)}$ in conjunction with temperature readings within the bar for the required boundary conditions. The use of the "Low-Noise" option on the Omega Quicklog ${ }^{\circledR}$ software

\begin{tabular}{|c|c|c|c|}
\hline MATERIAL & $\begin{array}{c}\mathrm{K} \\
\left(\mathrm{W} / \mathrm{m} .{ }^{0} \mathrm{C}\right) \\
\end{array}$ & $\begin{array}{c}\mathrm{C}_{\mathrm{P}} \\
\left(\mathrm{J} / \mathrm{kg}{ }^{\circ} \mathrm{C}\right)\end{array}$ & $\begin{array}{c}\rho \\
\left(\mathrm{Kg} / \mathrm{m}^{3}\right) \\
\end{array}$ \\
\hline Coating Z & 3.5 & 1070 & 3970 \\
\hline Coating HC & 17.0 & 444 & 8900 \\
\hline Coating M & 0.7 & 475 & 5680 \\
\hline Coating Y & 0.7 & 600 & 5000 \\
\hline \multirow[t]{2}{*}{ Carbon Steel } & $64.1-0.0427 \mathrm{~T}$ & $2368-1492 \mathrm{E}-2 \mathrm{~T}+4107 \mathrm{E}-5 \mathrm{~T}^{2}-$ & \\
\hline & & $4696 \mathrm{E}-8 \mathrm{~T}^{3}+1953 \mathrm{E}-11 \mathrm{~T}^{4}$ & 7200 \\
\hline \multirow[t]{2}{*}{ Aluminum } & $80(1)$, & 1084 (l) & 2700 \\
\hline & $220-0.77(\mathrm{~T}-525)(\mathrm{s})$ & $743-0.4985 \mathrm{~T}(\mathrm{~s})$ & \\
\hline \multirow[t]{2}{*}{$\mathrm{Al}-1.3 \% \mathrm{Si}$} & $80(1)$, & $1084(\mathrm{l})$ & 2700 \\
\hline & $220-0.77(\mathrm{~T}-525)(\mathrm{s})$ & $743-0.4985 \mathrm{~T}(\mathrm{~s})$ & \\
\hline \multirow[t]{2}{*}{$\mathrm{Al}-8.4 \% \mathrm{Si}$} & 64(1) & $976(\mathrm{l}), 900(\mathrm{~s})$ & 2680 \\
\hline & $176-0.77(\mathrm{~T}-455)(\mathrm{s})$ & 950 (mushy) & \\
\hline
\end{tabular}

Table 2. Thermophysical properties of materials used.

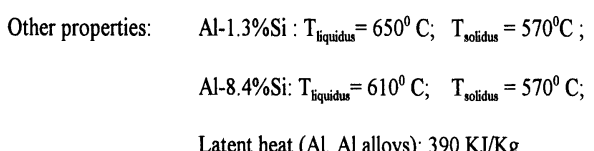

proved crucial in ensuring the accuracy of the temperature measurements.

For every condition, three experiments were carried out, each of them involving the three pairs of thermocouples. The values of peak heat flux reported varied within a $\pm 10 \%$ range. The following methodology was employed: for each coating, the same combinations of substrate speed and superheat were adopted. For some experiments, the metal column in the mold was also varied, so as to produce thinner or thicker strips.

The thermophysical properties for the liquid metal and alloys, together with those of the substrate and various coatings, are presented in Table 2.

\section{Results and Discussion}

The effects of the most important variables on solidification and cooling rates were studied by casting pure aluminum onto cold substrates of various coatings types and roughnesses, moving at various speeds.

\subsection{Effect of Coatings}

The overall appearances of the strips produced were very good. The smoother coatings generally yielded strips with smoother bottom surfaces. In most cases, the bottom surface of the strips had a smooth texture, while the free surface exhibited some roughness. In initial tests, holes and defects formed on the strips' bottom surfaces, indicated the presence of dissolved gas. Argon injection in the melt prior to casting reduced the problem considerably.

Figure 2 shows the calculated interfacial heat fluxes to the substrate for the eight coatings used. The standard conditions for these experiments were: substrate speed $=0.8$ $\mathrm{m} / \mathrm{s}$ and superheat $=10^{\circ} \mathrm{C}$. Since the thicknesses of the strips were found to be an important parameter for heat transfer, the results shown in Fig. 2 refer to strips of ap- 
(a)

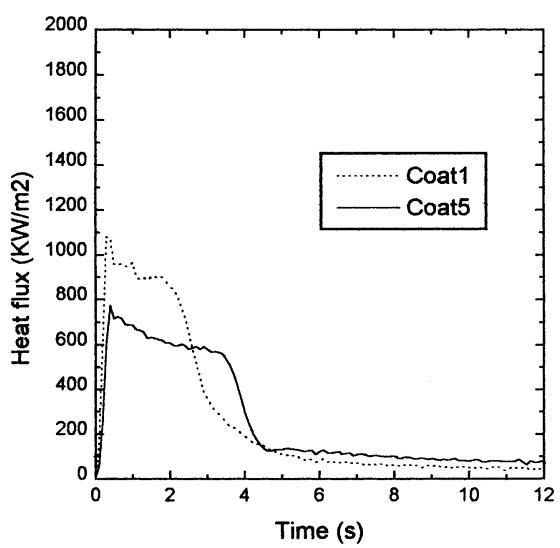

(b)
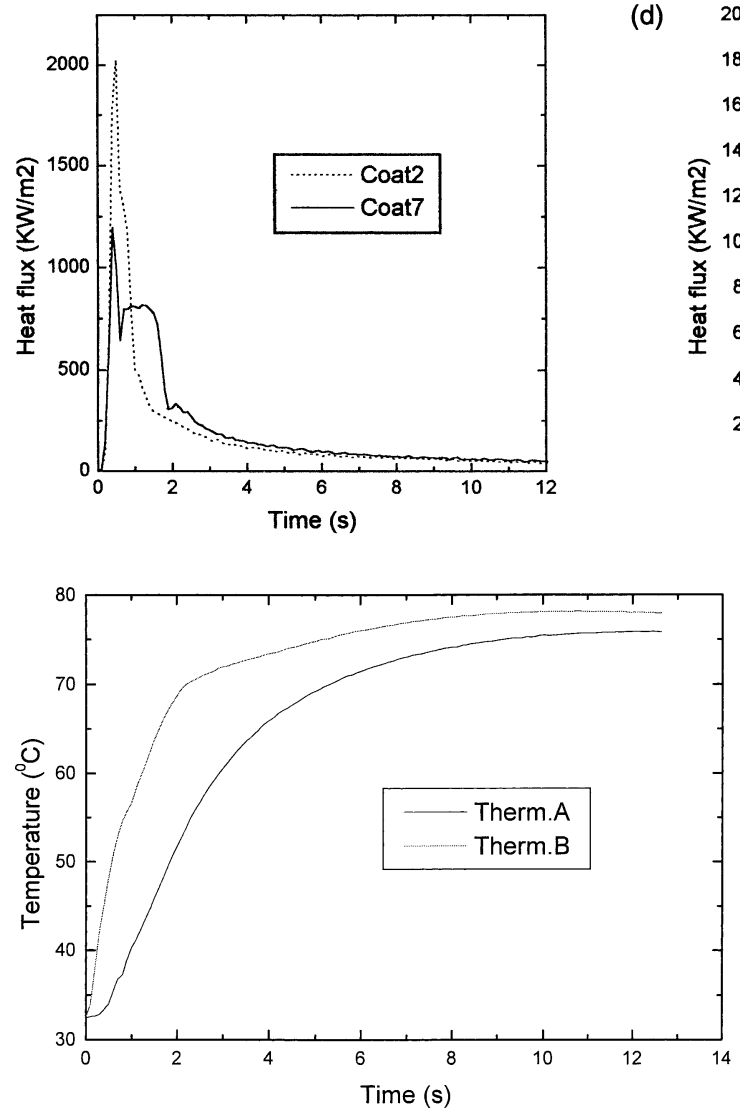

Fig. 3. Typical plot of the temperature evolution in the substrate (Therm. A at $4.87 \mathrm{~mm}$ from surface; Therm. B at $1.58 \mathrm{~mm}$ from surface).

proximately the same thickness $(2 \mathrm{~mm})$. A typical plot of the temperature evolution in the bar is given in Fig. 3 .

The heat fluxes were different for different substrates, for the same strip thickness, because of the different characteristics of the coatings. This could be proved by temperature measurements inside the strips. The coatings characteristics and their surface roughnesses were determined by the chemical and physical attributes of the coatings and deposition conditions, as already found by other researchers (see also Sec. 3.6). As one would expect, the only metallic coating used, matrix HC, gave superior results in terms of larger heat fluxes. Peaks of up to $3 \mathrm{MW} / \mathrm{m}^{2}$ were found for that type of coating, depending on conditions. The most insulative coating was the magnesium zirconate coating, with a

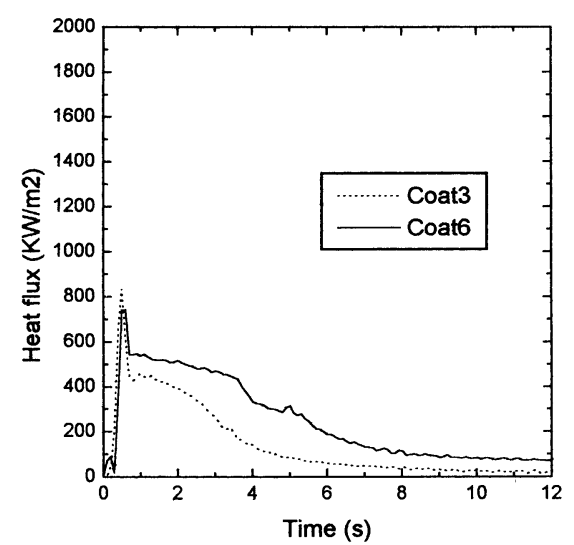

Fig. 2. Calculated interfacial heat fluxes for coatings: a) 1 and 5; b) 2 and 7 ; c) 3 and 6 and d) 4 and 8 .

peak around $0.7 \mathrm{MW} / \mathrm{m}^{2}$. Instantaneous heat fluxes were different, for the same strip thickness, because of the different deposition conditions, as discussed in page 10, 1.1. The coatings and their roughnesses are determined by deposition conditions, as already found by other researchers.

The transient peaks in the heat flux curves mark the point at which solidification of the interfacial layer of freezing metal or alloy is nearly completed. The drop in the heat flux thereafter is caused by contraction of the solidified layer, and consequent formation of an air gap between the coating and the decoupled shell. This was confirmed by estimation of the temperature on the bottom surface of the strip $\left(T_{\mathrm{bs}}\right)$, as shown in Sec. 3.7. This temperature usually reached the solidus temperature, by the time the peak heat flux occurred. In addition, the reduction in the temperature difference between the metal and the coating yields a further reduction in the heat fluxes. The peak in most cases occurred within 1 second of initial contact of the molten metal with the substrate. A time period ranging between 12 and $18 \mathrm{~s}$ was needed before the heat flux dropped to nearly zero. Here, it is important to note that, should the peak heat flux occurred earlier, it would have been detected, given the high frequency of data acquisition employed in the present work.

In some cases, the heat flux increased again almost immediately after the initial drop following the peak. This happened more often for thicker strips, the reason being that thicker strips solidify more slowly, allowing some remelting of the solidified layer, thereby improving the contact with the coating once more. The air gap would be the responsible for this phenomenon.

In order to check the accuracy of the one-dimensional 

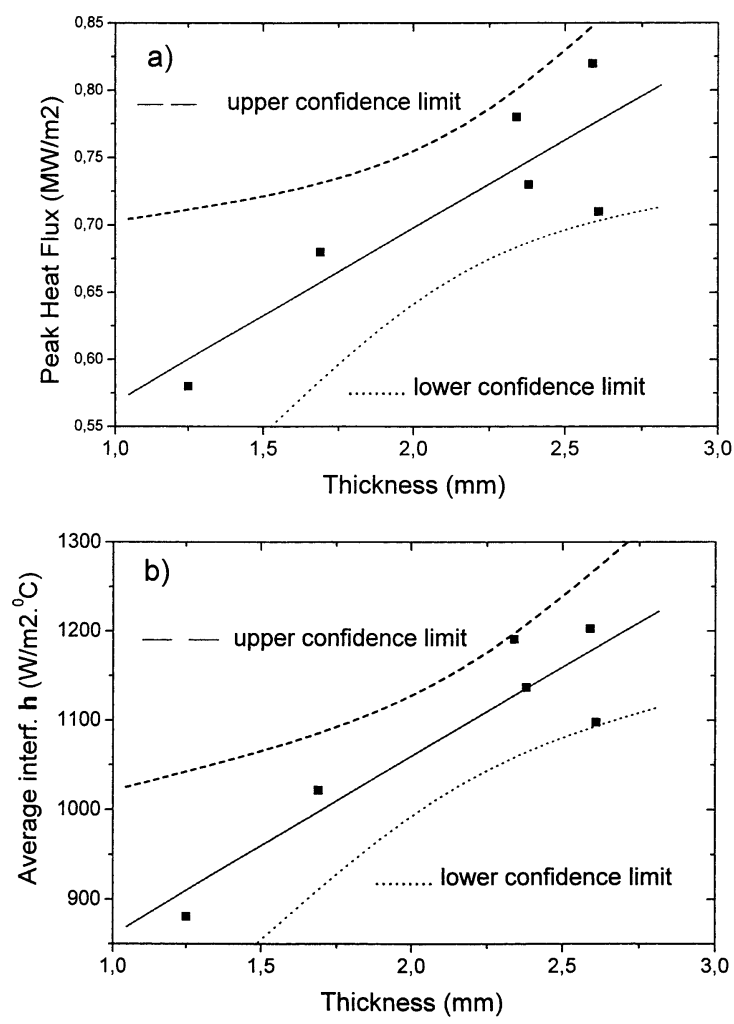

Fig. 4. Effect of strip thickness on the a) peak heat flux; b) interfacial heat transfer coefficient, for coating 5 .

heat transfer assumption, a global heat balance was carried out by inserting a thermocouple within the solidifying metal, at the same longitudinal position as one pair of thermocouples inserted in the substrate. The change in melt temperature was registered and the global heat balances of sensible heat losses to net heat extracted were close, and indicated random errors ranging from -5 to $+5 \%$. Therefore, the assumption of one-dimensional heat conduction was considered correct.

The effects of other variables, such as thickness of strip and superheat were evaluated for the whole range of coatings, but for the sake of brevity, only results for some coatings are now shown. Very good qualitative reproducibility was found for the diverse coatings, in terms of the variables mentioned.

\subsection{Effect of Strip Thickness}

Figure 4 gives the effect of the strip thickness on the peak heat flux and interfacial heat transfer coefficient, for coating 5, along with 95\% confidence limits. Despite some scatter, it is clear that a thicker strip yields a greater peak. The results seem to be in qualitative disagreement with those compiled by Wang and Matthys, ${ }^{1)}$ who advocated the following correlation between the average interfacial heat transfer coefficient and the thickness of the strip:

$$
h=18.9 \delta^{-0.82}
$$

where $\delta$ is the thickness of the strip. As such, the heat transfer coefficient would increase for thinner strips. However, as they pointed out, relatively few data are available on heat transfer coefficients for twin-belt casters. Indeed, reference to their figure where the data is plotted, clearly shows that most of the points for which the correlation was derived are for data from roll casters, while the few points for the twin-belt casters are all situated in the low-speed range. Furthermore, and more importantly, the type of interfacial contact is different between single and twin-belt processes, since in the latter there is no free surface and pressure on the metal is exerted from both sides.

A possible explanation for these single belt results is that the thicker strips exert slightly more downward (pressure) force on the bottom surface, improving its contact with the substrate, i.e., there is a slightly increased metallostatic head and delaying air gap formation. In order to confirm this tendency, some static tests were carried out with samples varying from 5 to $10 \mathrm{~mm}$ of thickness. Again, the peak heat fluxes increased with increased thickness, suggesting the explanation is plausible.

These results were valid for the range of velocities chosen for this study, between 0.4 and $1.2 \mathrm{~m} / \mathrm{s}$, and for strip thicknesses between 1 and $4 \mathrm{~mm}$. Very good reproducibility was found for a given type of coating, for both smooth and rough surfaces. It was also found that for some coatings the influence of strip thickness is more pronounced than for others.

An advantage of this experimental apparatus is that it is possible to induce the casting of thinner or thicker strips, according to the interest of the researcher. In this regard, the present methodology is more useful than conducting simple immersion (dipping) tests.

\subsection{Effect of Substrate Speed}

In this study, it was not possible to separate the effect of substrate speed from other variables, since there was no independant control, of the strip thickness with the present equipment. Nevertheless, considering that in an industrial process high speeds will generally yield thinner strips in a free form delivery system, one can expect lower peaks in the heat fluxes for thinner strips on single-belt casters, over the range of thicknesses studied in this work.

\subsection{Effect of Superheating}

A higher initial superheat was found to increase the peak heat flux. For coating 1, for example, the peak heat flux varied from approximately 1.1 to $1.4 \mathrm{MW} / \mathrm{m}^{2}$, for a superheat variation of $20^{\circ} \mathrm{C}$, and for the same thickness of strip $(2.3 \mathrm{~mm})$. This result is in agreement with earlier reports in the literature, except for the work of Strezov and Herbertson, ${ }^{5)}$ who found lower peak heat fluxes for higher superheats. Similarly, a finer microstructure for a higher melt superheat was obtained. This is in agreement with Muojekwu et al. ${ }^{11)}$ and in disagreement with Strezov and Herbertson. $^{5)}$

In order to assess the effect of the initial superheat on the peak heat flux, for different thicknesses, a correlation of the type:

$$
\frac{q_{\mathrm{P}}}{\Delta T^{m}}=a T_{\mathrm{h}}+b
$$

was assumed, where $\Delta T$ is the superheat and $q_{\mathrm{P}}$ is the peak heat flux and $\delta$ is the thickness. The value of $m$ that gave the best fit was 0.2 , for all coatings. Very good agreement was obtained between this correlation and the experimental data, as can be seen in Fig. 5a), for coating 1, and the corresponding relationship between the average interfacial heat transfer coefficient, and strip thickness and initial superheat 

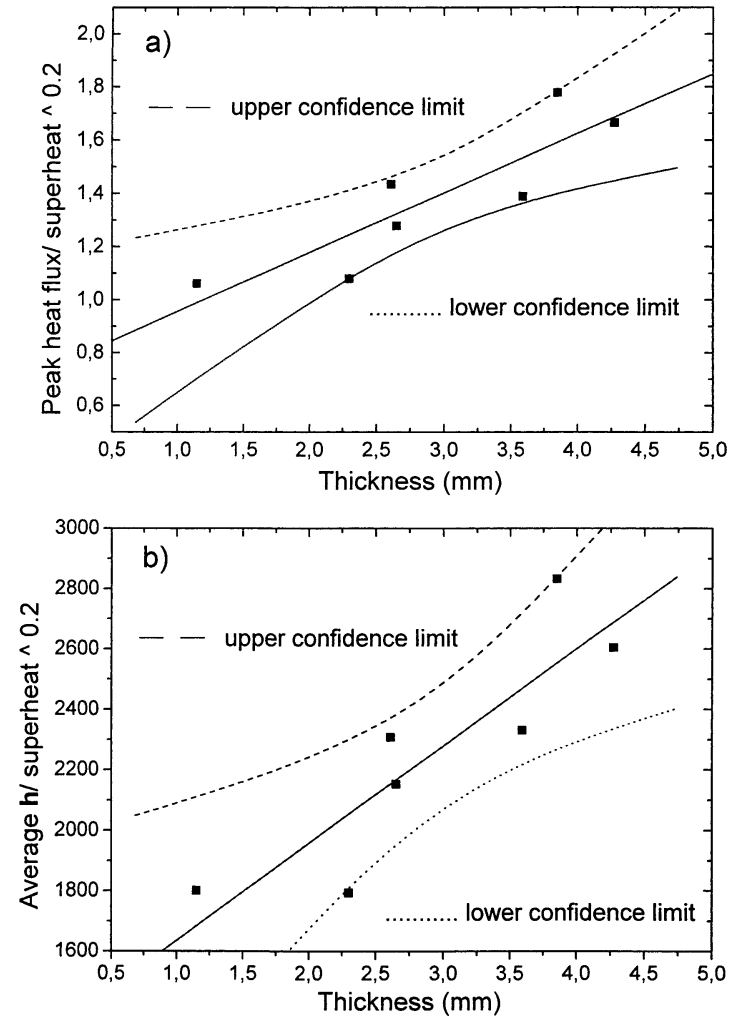

Fig. 5. Combined effect of superheat and strip thickness on the a) peak heat flux; b) interfacial heat transfer coefficient, for coating 1 .

is shown in Fig. 5b).

Higher superheats yielded smoother bottom surfaces of the strips. As already discussed by previous researchers, ${ }^{3,11-12)}$ improved fluidity and a lower surface tension at higher superheats contribute to a better wettability of the substrate, resulting in a rather smoother bottom surface. On the free surface, no significant difference was observed.

Elevated superheats produced thinner strips. Similar trends have been reported by Chen et $a l .^{3)}$ In the present work, this effect may have been caused by the reduction in the air gap thickness at a higher superheat. Another possibility mentioned by other authors, ${ }^{3)}$ is the spreading of the metal out to the sides caused by a delay in the onset of solidification. This did not apply to the system used in this work, since any flows were constrained by the sides of the groove. Visual inspection of the strip allowed one to conclude that any variations in the width of the strip, at different superheats, were minimal.

\subsection{Variation of Heat Flux with Time}

In the study of interfacial heat transfer, it is important to determine not only the peak heat fluxes, but also the heat flux characteristics following solidification of the interfacial layer. Kumar and Prabhu ${ }^{13)}$ have proposed a correlation between heat flux and the peak heat flux, for the solidification of bars of aluminum base alloys. The correlation is based on the thermal diffusivity of the substrate and was able to predict the heat fluxes following the ocurrence of a peak heat flux.

Muojekwu et al. ${ }^{11)}$ have suggested two different stages after the peak. In the first, the heat flux falls linearly with time while in the second, the relation between $q$ and the peak heat flux $q_{\mathrm{P}}$ depends on the coefficients of linear expansion of the casting and the mold, and on the thermal diffusivity of the mold.

In the present work, since only one type of substrate was used (i.e. steel bars), a simpler correlation was proposed:

$$
\frac{q}{q_{\mathrm{P}}}=A t^{-c}
$$

where $t$ represents the time elapsed after the peak heat flux, and $c$ is the fitting coefficient.

In some cases, mentioned in Sec. 3.1, a plateau follows the ocurrence of the peak. In these cases, the applicability of the correlation is limited to the points after the plateau, i.e., where there is a sharp drop in the heat flux. For the points after the plateau, the best correlation proved to be:

$$
\frac{q}{q_{\mathrm{P}}}=A_{1} e^{-d t}
$$

where $t$ represents the time elapsed after the plateau, and $d$ is the fitting coefficient.

Figure 6 shows the fitted curves for the heat fluxes in the region after the peak or after the plateau, if it happens, for the smooth coatings, for the standard conditions (substrate speed $=0.8 \mathrm{~m} / \mathrm{s}$; initial superheat $=10^{\circ} \mathrm{C}$ ). There was very good agreement between the curves and the experimental values. Values for the fitting parameters $A, A_{1}, c$ and $d$ for all coatings are given in Table 3.

\subsection{Effect of Roughness}

The heat flux values for metallic (nickel based) coatings $\mathrm{HC}$ were found to be much higher than those for the others, in the case of a smooth surface. For rough surfaces, the coatings lead to lower peaks, as expected, and the difference among the coatings was also smaller. One can observe that the effect of substrate roughness is different for every coating. Similar findings were reported by Wang et al., ${ }^{12}$ ) who found little variation in $h$ for the solidification of copper onto smooth and rough stainless steel substrates. For coating $\mathrm{HC}$, there was a decrease of $45 \%$ in the heat transfer using a rough substrate, whereas for coating $M$, the decrease was about $17 \%$. The wettability properties of the coatings were outside the scope of this study, but will hopefully be included in future work. Such data would hopefully lead to a better understanding of the results obtained, and the interfacial heat flux phenomena involved.

It is relevant to note that the levels of roughness of the bars used for the present studies were relatively high. Values of $R_{\mathrm{a}}$ between 11 and $18 \mu \mathrm{m}$ are well above data encountered in the literature. Therefore, even higher values for $q$ and $h$ can be expected, if a smoother substrate is to be used.

Once again the results confirm earlier reports in the literature, except for the recent work of Strezov and Herbertson, ${ }^{5)}$ who reported an opposite pattern (higher peak heat fluxes for rougher substrates).

\subsection{Estimation of Transient Heat Transfer Coeffi- cients}

The interfacial heat transfer coefficients can be calculated by considering the transient heat flux from the cast to the point where the thermocouple is located, $4.57 \mathrm{~mm}$ below 
(a)

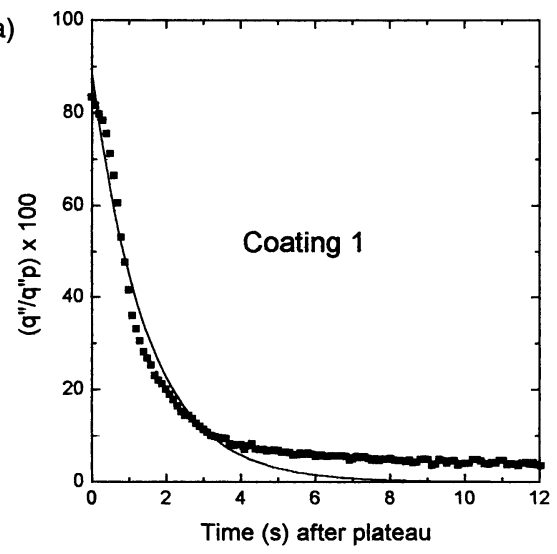

(b)

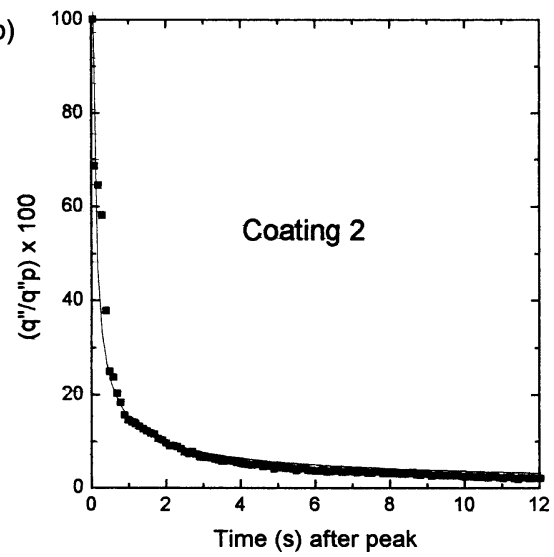

(c)

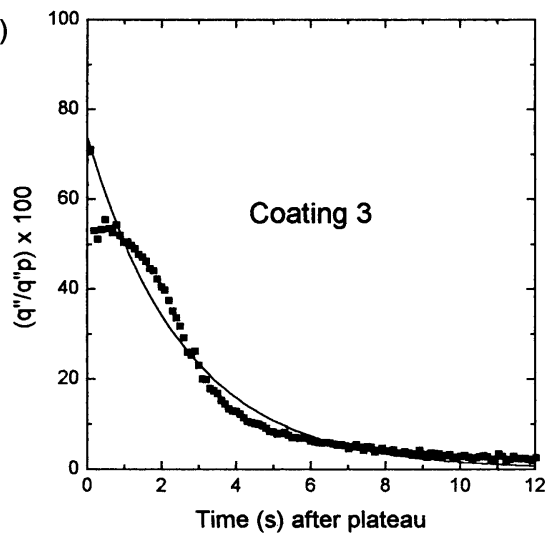

(d)

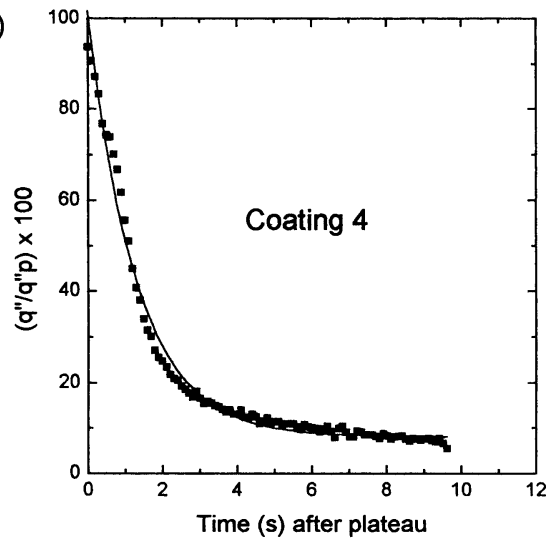

Fig. 6. Variation in normalized interfacial heat fluxes versus contact times following peaks or plateaux in interfacial heat fluxes, for coatings 1 (a); 2 (b); 3 (c), and 4 (d).
Table 3. Constants for Eqs. (5) and (6).

\begin{tabular}{ccccc}
\hline Coating & $\mathrm{A}\left(\mathrm{sec}^{-1}\right)$ & $\mathrm{A}_{1}$ & $\mathrm{c}$ & $\mathrm{d}\left(\mathrm{sec}^{-1}\right)$ \\
\hline 1 & & 0.8916 & & 0.68117 \\
2 & 0.15 & & 0.631 & \\
3 & & 0.79071 & & 0.5177 \\
4 & & 0.9362 & & 0.7726 \\
5 & & 0.6792 & & 1.5367 \\
6 & & 0.6268 & & 0.2863 \\
7 & 0.231 & & 0.541 & \\
8 & & 0.6207 & & 0.5358 \\
\hline
\end{tabular}

the surface. The total thermal resistance $\left(R_{\mathrm{T}}\right)$ of the system in the present case will be due to three contributions:

- the interfacial thermal resistance $\left(R_{\mathrm{i}}=1 / h\right)$;

- the resistance due to conduction through the coating $\left(R_{\mathrm{c}}\right)$;

- the resistance due to conduction through the substrate $\left(R_{\mathrm{s}}\right)$ to the measuring thermocouple.

Mathematically:

$$
R_{\mathrm{T}}=R_{\mathrm{i}}+R_{\mathrm{C}}+R_{\mathrm{S}}
$$

The calculation of the thermal resistance to conduction through the coating and the substrate involves two components:

$$
R_{\mathrm{C}}=\frac{\delta_{\mathrm{C}}}{k_{\mathrm{C}}} ; \quad R_{\mathrm{S}}=\frac{\delta_{\mathrm{S}}}{k_{\mathrm{S}}}
$$

Given a coating thickness $\delta_{\mathrm{C}}$ of $75 \mu \mathrm{m}$ and the depth of the thermocouple, $\delta_{\mathrm{S}}$, of $4.57 \mathrm{~mm}$, then:

$$
q(t)=\frac{T_{\mathrm{bs}}-T_{\mathrm{S}}}{R_{\mathrm{T}}}
$$

where $T_{\mathrm{bs}}$ is the transient temperature on the bottom surface of the strip, and $T_{\mathrm{S}}$ is the transient temperature $4.57 \mathrm{~mm}$ below the substrate surface, which was measured. On the other hand, $T_{\mathrm{bs}}$ was evaluated from a heat conduction model, involving phase change.

The temperature $T_{\mathrm{bs}}$ and the transient interfacial heat transfer coefficients were calculated from a heat conduction/solidification model. The heat flux calculated by the inverse model was used as boundary condition. An equivalent specific heat was assumed, to take into account the release of latent heat. Heat transfer by radiation and convection was considered on the interface. On the extremities (top surface of the strip and bottom of the substrate), heat was also lost by radiation and convection. The emissivity of the top surface of the aluminum/alloy was considered as 0.20 and the shape factor was 1 . The heat transfer coefficient for natural convection was considered $10 \mathrm{~W} / \mathrm{m}^{2} \cdot \mathrm{K}$. A typical calculated $T_{\mathrm{bs}} \times$ time curve is presented in Fig. 7. It can be seen that the solidification at the interfacial layer $\left(T=660^{\circ} \mathrm{C}\right.$ for pure aluminum) starts at approximately $0.5 \mathrm{~s}$, coinciding with the occurrence of the peak heat flux.

It is shown in Fig. 8 that the evolution in the heat transfer coefficient, $h$, follows the same profile as the heat fluxes. This is not surprising, considering the rapid solidification of the strip. This means that there is a relatively small increase in the substrate temperature. Similar results were found by Chen et $a l .{ }^{3)}$ and Spitzer, ${ }^{14)}$ who worked with a similar ap- 
paratus.

The minimum values of $R_{\mathrm{T}}$, corresponding to the peaks in $\mathrm{h}$, ranged from $3.08 \mathrm{E}-3 \mathrm{~m}^{2} \cdot \mathrm{K} / \mathrm{W}$ for coating 2 to $8.08 \mathrm{E}-3 \mathrm{~m}^{2} \cdot \mathrm{K} / \mathrm{W}$ for coating 5 .

Another interesting aspect to be assessed is the relative importance of heat transfer through the various coatings. In the case of the smooth metallic coating $\mathrm{HC}$, the average thermal resistance through the coating accounted for as little as $1.4 \%$ of the total thermal resistance. The interfacial (air gap) resistance represented $89 \%$ of $R_{\mathrm{T}}$. For the rough metallic coating, the resistance through the coating was even lower, at $0.85 \%$ of $R_{\mathrm{T}}$. Contrarily, in the case of the smooth coating $\mathrm{M}$, the following results were found: $17.6 \%$ of $R_{\mathrm{T}}$ due to the coating and $77.6 \%$ due to the interfacial (air gap) resistance.

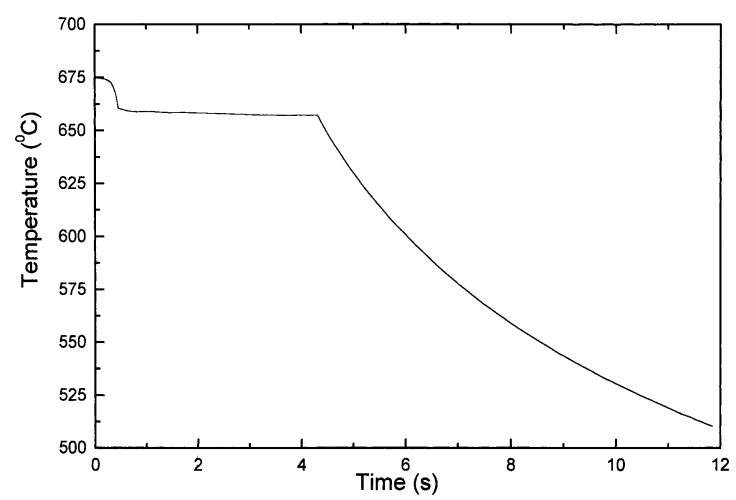

Fig. 7. Typical plot of the $T_{\mathrm{bs}}$ evolution.

\subsection{Evolution of $\boldsymbol{h}$ after the Peak}

In the analysis of the heat fluxes and heat transfer coefficients, it is important to stress not only the peak values, but also the evolution of $q$ and $h$ after the peak, before solidification is complete. In this work, a relationship between the peak values and the occurrence, or not, of a plateau following the peak, was generally observed. The higher the peak, the less likely was the occurence of the plateau.

In order to quantify this relationship, a simple criterion was chosen. The time elapsed from the peak ocurrence to the moment when $h$ reaches a value of $0.25 h_{\mathrm{p}}$ was calculated for the various coatings. The reason for choosing this value is due to observations that, once $0.25 h_{\mathrm{p}}$ is reached, the heat transfer coefficient in most cases remained stable or fell slightly. This is a fairly good indication that the solidification was complete. The value $0.25 h_{\mathrm{p}}$ was an approximation, and comes from empirical observation. It was observed that the heat transfer coefficient reaches stability when the only heat to be transferred is the sensible heat. This assumption was confirmed by the calculation of the temperature through the thickness of the strip during the solidification/cooling process. Whenever the heat transfer coefficient reached the value $0.25 h_{\mathrm{p}}$, temperatures throughout the strip were below the solidus temperature.

Table 4 gives the results obtained for the different coatings deposited on smooth substrates. The data suggest that not only did the metallic coating result in higher peak heat fluxes, but the solidification process was also finished earlier. This information is useful for industrial processes, since (a)

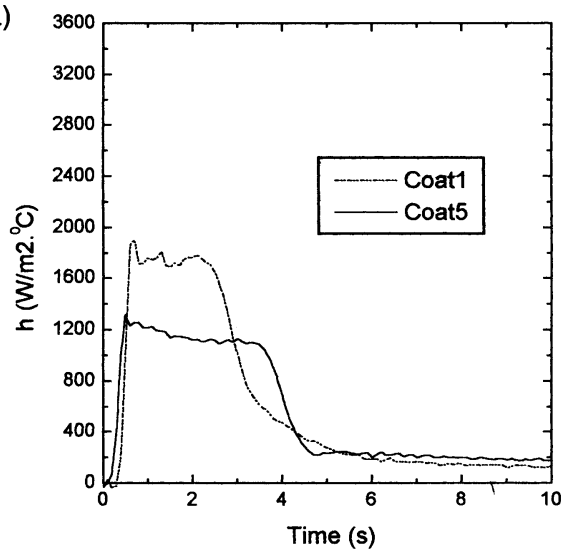

(b)

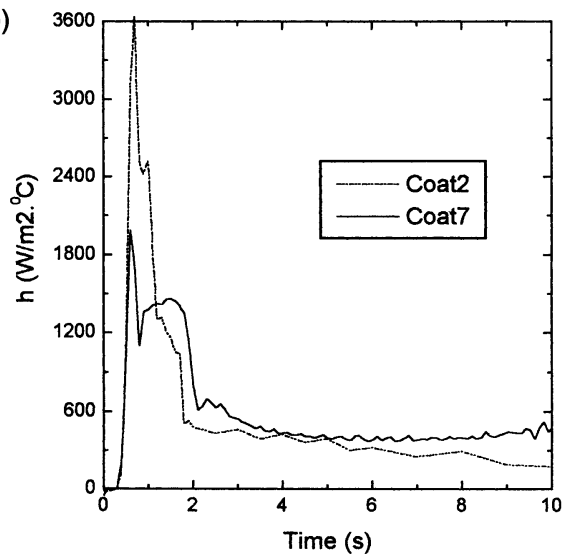

(c)

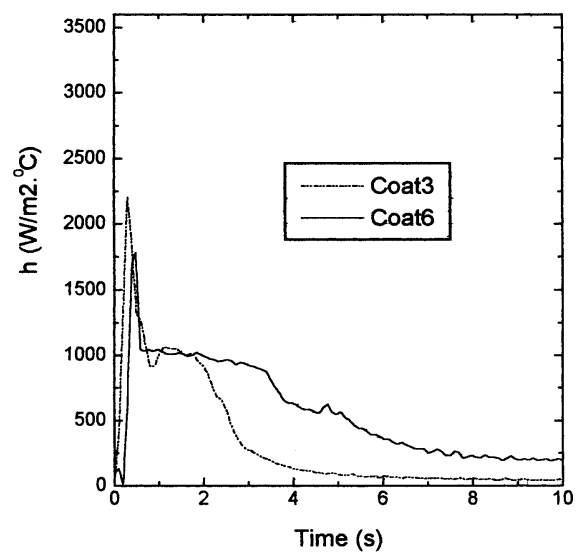

(d)

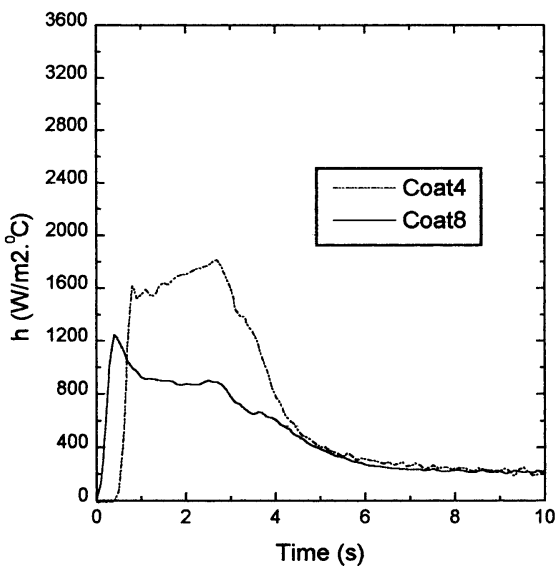

Fig. 8. Calculated interfacial heat transfer coefficients for coatings: a) 1 and 5; b) 2 and 7; c) 3 and 6 and d) 4 and 8 . 
Table 4. Time delay between $h_{\mathrm{P}}$ and $h=0.25 h_{\mathrm{p}}$.

\begin{tabular}{cc}
\hline Coating & $\mathrm{t}_{(\mathrm{h}=0.25 \mathrm{hp})}-\mathrm{t}_{\mathrm{p}}(\mathrm{s})$ \\
\hline 1 & 4.1 \\
2 & 1.5 \\
3 & 3.8 \\
4 & 4.7 \\
\hline
\end{tabular}

it can be readily related to the productivity of a single-belt machine. On the other hand, coating Y yielded a heat flux curve with the most extended plateau, after its peak. This characteristic makes up for its much lower peak value, in terms of total heat extracted.

\subsection{Air Gap Evolution}

In the region of the air gap, the heat is transferred by conduction through the gap so that $(q=h \Delta T \cong k \Delta T / \Delta x)$, and the air gap thickness is related to the conductivity of the air and the heat transfer coefficient according to:

$$
\Delta x=\frac{k_{\text {air }}}{h}
$$

It is well accepted in the literature that what is commonly called "air gap" appears due to the contraction and separation of the solidifying layer from the substrate. In most of our experiments, the interfacial layer reached the solidus temperature at approximately $0.5 \mathrm{~s}$. To corroborate this assertion, one can add that the heat transfer coefficient would simultaneously drop sharply at that time $(0.5 \mathrm{~s})$. It is also important to stress that the metal does not fully wet the substrate at the first moment of contact, so an initial air gap is also expected. If not, initial heat fluxes would have been orders of magnitude greater for perfect thermal contact.

As seen in Fig. 9, the air gap grows rapidly, up to the point where the solidification might be finished, following a contact time approximately equal to $6 \mathrm{~s}$. After that, there is a slight and erratic increase in the calculated air gap. The reason for this could not be determined. One possible explanation might be the growth of an oxide film on the metal's surface, as observed by Ho and Pehlke. ${ }^{15)}$ This oxide film, being of higher thermal resistance than the pure metal, would lead to a further reduction in the calculated heat transfer coefficient in that region $(t>6 \mathrm{~s})$ and, as a consequence, an increase in the calculated air gap. It is not clear, however, that there would be enough time for the formation of such oxide. Further, there was no deterioration in the heat extraction characteristics of the bar in subsequent experiments.

A more realistic explanation is probably the existence of a normal fluctuation around a roughly stabilized value of the air gap, as observed in the heat transfer coefficient (Fig. $8 \mathrm{~d})$ ). In that region $(t>6 \mathrm{~s})$, the numerical method is more sensitive to experimental error, given the stabilization in the heat transfer coefficient. The air gap was found to reach a final value around $200 \mu \mathrm{m}$.

\subsection{Uncertainty Analysis}

Since there is no manual interpolation of data in the present calculations, the level of uncertainty is not very high. Also, some restrictions were employed to ensure stability of the IHCP (Inverse Heat Conduction Problem) solution, for

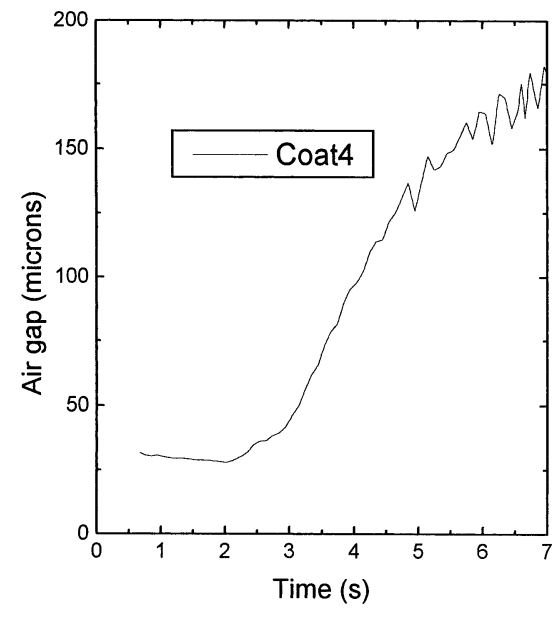

Fig. 9. Calculated air gap evolution for coating 4 .

the small time steps employed in the present case.

Some calculations were repeated using the method of Hills, ${ }^{16)}$ to check the uncertainty due to the IHCP solution. The differences, in most cases, amounted to a maximum of $10 \%$. No bias was considered, since the thermocouples were calibrated and also because in the specific case the random errors are considered much more relevant.

Using Kline's method ${ }^{17)}$ to calculate the total uncertainty and considering the most important variables as the thickness of the strip and the initial superheat, the total uncertainty is calculated by:

$$
\left(\frac{W_{h}}{h}\right)^{2}=\left(\frac{\partial \ln h}{\partial \ln \delta} \cdot \frac{W_{\delta}}{\delta}\right)^{2}+\left(\frac{\partial \ln h}{\partial \ln \Delta T} \cdot \frac{W_{\Delta T}}{\Delta T}\right)^{2}+\left(\frac{W_{\exp }}{h}\right)
$$

where:

$$
\frac{\partial \ln h}{\partial \ln \delta}=1 ; \quad \frac{\partial \ln h}{\partial \ln \Delta T}=0.2
$$

These values were approximately representative of the various conditions used in this work. The relative errors, $W_{\delta} / \delta$, (due to the variation in the thickness of the strip) and $W_{\Delta T} / \Delta T$ (due to uncertainties in the measurement of the initial superheat) were estimated to be 0.20 and 0.10 , respectively. Since the experimental error $\left(W_{\text {exp }} / h\right)^{2}$ due to the temperature measurements was estimated to be about 0.10 , the total uncertainty would be about $15 \%$ for the method adopted.

\subsection{Comparison with Data in the Literature}

As mentioned earlier in this paper, little data are available for conditions similar to those pertaining to this work. One of the main purposes of the authors was to simulate a casting process with a moving substrate and a free surface, at casting speeds and strip thicknesses similar to single-belt processes currently under development. Therefore, any attempt to compare the results of this work to others is a tricky task.

Nevertheless, the values of heat flux and heat transfer coefficients obtained here are in the range of data recently published for the various near-net-shape casting configurations. For example, Wang and Matthys recent literature review $^{1)}$ reports values in the range of 850 and $2900 \mathrm{~W} / \mathrm{m}^{2} \cdot \mathrm{K}$ 
for steel castings, at low speeds and at thicknesses between 20-80 mm. Our work concentrated on a speed range of $0.4-$ $1.2 \mathrm{~m} / \mathrm{s}$ and thicknesses ranging from $1-5 \mathrm{~mm}$.

Recently, Strezov and Herbertson ${ }^{5)}$ used a more sensitive data acquisition system, for the heat transfer between a copper substrate embedded in a paddle and a stainless steel bath where the paddle was immersed and found peak heat fluxes much higher. They measured peaks in the order of $10-20 \mathrm{MW} / \mathrm{m}^{2}$, while the present authors found peaks of up to $3 \mathrm{MW} / \mathrm{m}^{2}$. In order to reconcile these large differences, the following points can be made:

Firstly, the cast metals and the substrates were different for the two investigations. From the review of Wang and Mathhys, ${ }^{1)}$ it can be seen that the use of a copper substrate, instead of a carbon steel one, usually doubles heat fluxes. From the investigation of Farouk, Apelian and Kim, ${ }^{2)}$ it is seen that heat fluxes for steel castings are also roughly double heat fluxes for aluminum casting. According to this reasoning, the corresponding peak heat fluxes for the present work would be expected to range between 2.5 and $5 \mathrm{MW} / \mathrm{m}^{2}$, or one-fourth of their peak values. Secondly, the type of contact between the metal and substrate is obviously different, making it difficult to compare the results obtained.

Strezov and Herbertson also observed that the peak usually occurred a little earlier, at $10 \mathrm{~ms}$, whereas in the present work, the peak was observed at approximately $100 \mathrm{~ms}$. As mentioned before, direct simulations have shown that, had the peak occurred earlier, it would have been detected. The differences may be due to the much higher thermal diffusivity of the copper versus steel substrates, and differences in initial gas dynamics between the melt and substrates. Alternately, thermocouples placed very close $(100 \mu \mathrm{m})$ to the substrate might detect local heat fluxes associated with direct liquid metal-substrate contact associated with protruding peaks. Further investigation is needed to clarify these differences.

\section{Conclusions}

An experimental apparatus has been developed and sucessfully used to simulate thin strip casting of aluminum and aluminum alloys. The most important variables affecting the casting process were sucessfully investigated, such as the type of coatings, substrate roughness, strip thickness and initial superheat. The interfacial heat fluxes were calculated by an IHCP method. From the heat fluxes calculated, it was possible to determine the heat transfer coefficients and the local cooling rates.

Based on the results obtained, the following conclusions can be drawn:

(1) For the standard conditions of $10^{\circ} \mathrm{C}$ superheat and substrate speed of $0.8 \mathrm{~m} / \mathrm{s}$, heat fluxes ranged between 0.66 $\mathrm{MW} / \mathrm{m}^{2}$ and $2.0 \mathrm{MW} / \mathrm{m}^{2}$. Corresponding heat transfer coefficients for the various coatings ranged from 1200 and $3600 \mathrm{~W} / \mathrm{m}^{2} \cdot{ }^{\circ} \mathrm{C}$. These results demonstrate the critical importance of the metal-coating-substrate contact in the efficiency of heat transfer;

(2) Interfacial heat fluxes were found to be dependent on the thickness of the strips, initial superheat and proper- ties of the coatings (roughness, thermal conductivity). A thicker strip and a higher initial superheat increase interfacial heat fluxes. The importance of strip thickness in this configuration can be explained by the existence of a free surface which exerts no pressure on the solidifying strip, except for the metallostatic head. Smoother surfaces were found to be significantly more efficient in promoting heat transfer between substrates and the molten metal;

(3) Correlations were derived in order to predict peak heat fluxes and peak $h$ 's for different superheats and thicknesses, and also to predict heat fluxes after the peak. Very good agreement was found between the experimental values and the values predicted by the correlations for all coatings used in this work;

(4) A relationship was generally observed between the peak in the heat transfer coefficient and the occurence of a plateau following the peak. The higher the peak, the less likely the occurence of the plateau. A simple criterion was proposed to quantify this relationship. The information here obtained is considered useful for industrial processes;

(5) Some scatter was present in the results. However, consistent qualitative agreement was found in the vast majority of simulated conditions.

\section{Acknowledgments}

The authors gratefully acknowledge the technical support provided by Hazelett Strip Casting Corporation, in applying the coatings to the substrates used in the present work. The first two authors also wish to thank the Conselho Nacional de Desenvolvimento Científico e Tecnológico-CNPq, Brasil, for financial support.

\section{REFERENCES}

1) G. X. Wang and E. F. Matthys: Proc. of Melt Spinning, Strip Casting and Slab Casting, TMS, Warrendale, PA, (1996), 205.

2) B. Farouk, D. Apelian and Y. G. Kim: Metall. Trans. B, 23B (1992), 477.

3) J. S-J. Chen, R. C. Ren and A. A. Tseng: J. Mater. Process. \& Manufacturing, 3 (1995), 373.

4) A. Couture, R. Angers, M. R. Krishnadev, E. Es-Sadiqui and J. Masounave: Can. Metall. Q., 31, (1992), No 5, 63.

5) L. Strezov and J. Herbertson: ISIJ Int., 38, (1998), No. 9, 959.

6) W. Reichelt, U. Urlau, R. Nystrom and E. Burstrom: Proc. Metec 94, 2nd European Conf. on Continuous Casting, VDF, Düsseldorf, (1994).

7) J. Allen: Hazelett Strip Casting Corporation, Private comunication (1996).

8) P. G. Q. Netto, R. P. Tavares and R. I. L. Guthrie: Internal Report, McGill University, (1996).

9) C. Jefferies: Ph.D. Thesis, McGill University, Dep. of Mining and Metallurgical Engineering, (1995), 1.

10) J. V. Beck, B. Blackwell and C. R. St. Clair, Jr.: Inverse Heat Conduction: Ill-posed Problems, Wiley Interscience, New York, (1985), 308

11) C. A. Muojekwu, I. V. Samarasekera and J. K. Brimacombe: Metall. Trans. B, 26B (1995), 361.

12) G. X. Wang and E. F. Matthys: J. Heat Transfer, 118 (1996), 157.

13) T.S. Prasanna Kumar and K. Narayan Prabhu: Metall. Trans. B, 22B (1991), 717.

14) H. Spitzer: Int. J. Heat Mass Transfer., 34, (1991), No. 8, 1969.

15) K. Ho and R. D. Pehlke: Metall. Trans. B, 16B (1985), 585.

16) R. G. Hills and E. C. Hensel, Jr.: Numer. Heat Transfer, 10 (1986), 369.

17) S. J. Kline: J. of Fluid Engineering (ASME), 107 (1985), 153. 